\title{
Effect of vitamin D supplementation in patients with chronic hepatitis $C$ after direct-acting antiviral treatment: a randomized, double-blind, placebo-controlled trial
}

\author{
Supachaya Sriphoosanaphan ${ }^{1,2}$, Kessarin Thanapirom ${ }^{1,2,3}$, Stephen J Kerr ${ }^{4}$, Sirinporn Suksawatamnuay ${ }^{1,2,3}$, \\ Panarat Thaimai ${ }^{1}$, Sukanya Sittisomwong ${ }^{1}$, Kanokwan Sonsiri $^{1}$, Nunthiya Srisoonthorn ${ }^{2}$, Nicha Teeratorn ${ }^{1}$, \\ Natthaporn Tanpowpong ${ }^{5}$, Bundit Chaopathomkul ${ }^{5}$, Sombat Treeprasertsuk ${ }^{1}$, Yong Poovorawan ${ }^{6}$, Piyawat \\ Komolmit ${ }^{\text {Corresp. 1, 2, } 3}$ \\ ${ }^{1}$ Division of Gastroenterology, Department of Medicine, Faculty of Medicine, Chulalongkorn University, Bangkok, Thailand \\ 2 Center of Excellence in Liver Diseases, Thai Red Cross, King Chulalongkorn Memorial Hospital, Bangkok, Thailand \\ 3 Liver Fibrosis and Cirrhosis Research Unit, Chulalongkorn University, Bangkok, Thailand \\ 4 Biostatistics Excellence Center, Department of Research Affairs, Chulalongkorn University, Bangkok, Thailand \\ 5 Department of Radiology, Faculty of Medicine, Chulalongkorn University, Bangkok, Thailand \\ 6 Center of Excellence in Clinical Virology, Faculty of Medicine, Chulalongkorn University, Bangkok, Thailand \\ Corresponding Author: Piyawat Komolmit \\ Email address: pkomolmit@yahoo.co.uk
}

Background. Replacement of vitamin D (VD) among patients with chronic hepatitis C (CHC) before viral eradication has demonstrated a protective effect on serum markers associated with hepatic fibrogenesis. We therefore hypothesized that VD may facilitate further fibrosis amelioration following curative treatment with direct-acting antivirals (DAA).

Methods. This study was a randomized, double-blind, placebo-controlled trial conducted between February 2018 and August 2018. Patients with CHC and VD deficiency were randomized in a 1:1 ratio to either receive ergicalciferol or placebo over 6 weeks. Biochemical analysis indicators, including 25hydroxyvitamin $\mathrm{D}(25(\mathrm{OH}) \mathrm{D})$ ), fibrogenic markers [(transforming growth factor beta 1 (TGF- $\beta 1$ ) and tissue inhibitors of matrix metalloproteinases 1 (TIMP-1)], and fibrolytic markers [matrix metalloproteinase 9 (MMP-9) and amino terminal type III procollagen peptide (P3NP)], were assessed at baseline and at 6 weeks. Serum $25(\mathrm{OH})$ D was analyzed by a chemiluminescence immunoassay. Serum hepatic fibrogenesis markers were measured using a quantitative sandwich enzyme-linked immunosorbent assay.

Results. Seventy-five patients with $\mathrm{CHC}$ and VD deficiency were randomly assigned to VD $(n=37)$ and placebo $(n=38)$ groups. At the end of the study, the mean serum $25(\mathrm{OH}) \mathrm{D}$ level had risen to a normal level in the VD group, but was still deficient in the placebo group $(41.8 \pm 9.1 \mathrm{vs} .18 .1 \pm 4.6 \mathrm{ng} / \mathrm{mL}$, $p<0.001)$. Upon restoration of the VD level, there were no significant mean differences in the change from baseline for TGF- $\beta 1$ ( $-0.6 \mathrm{ng} / \mathrm{mL}$ ( $95 \%$ confidence interval (95\% CI) $-2.8-1.7), p=0.63)$, TIMP-1 ( -5.5 $\mathrm{ng} / \mathrm{mL}(95 \% \mathrm{Cl}-26.4-15.3), \mathrm{p}=0.60)$, MMP-9 (122.9 ng/mL (95\%Cl $-69.0-314.8), \mathrm{p}=0.21)$, and P3NP $(-0.1 \mathrm{ng} / \mathrm{mL}(95 \% \mathrm{Cl}-2.4-2.2), \mathrm{p}=0.92)$ between the VD and placebo groups.

Conclusion. Short-term VD supplementation after DAA treatment in patients with CHC does not improve serum fibrogenesis markers and may not expedite the residual liver fibrosis healing process. Future studies are warranted to evaluate the long-term effect of VD supplementation on hepatic fibrosis regression. 
1 Effect of vitamin D supplementation in patients with chronic hepatitis $\mathbf{C}$ after

2 direct-acting antiviral treatment: a randomized, double-blind, placebo-

3 controlled trial

4

5 Supachaya Sriphoosanaphan ${ }^{1,2}$, Kessarin Thanapirom ${ }^{1,2,3}$, Stephen J. Kerr ${ }^{4}$, Sirinporn

6 Suksawatamnuay ${ }^{1,2,3}$, Panarat Thaimai ${ }^{1}$, Sukanya Sittisomwong ${ }^{1}$, Kanokwan Sonsiri ${ }^{1}$, Nunthiya

7 Srisoonthorn ${ }^{2}$, Nicha Teeratorn ${ }^{1}$, Natthaporn Tanpowpong 5 , Bundit Chaopathomkul ${ }^{5}$, Sombat

8 Treeprasertsuk ${ }^{1}$, Yong Poovorawan ${ }^{6}$, Piyawat Komolmit ${ }^{1,2,3}$

9

10

11

12

13

14

15

16

17 18

${ }^{1}$ Division of Gastroenterology, Department of Medicine, Faculty of Medicine, Chulalongkorn University, Bangkok, Thailand

${ }^{2}$ Center of Excellence in Liver Diseases, King Chulalongkorn Memorial Hospital, Thai Red Cross, Bangkok, Thailand

${ }^{3}$ Liver Fibrosis and Cirrhosis Research Unit, Chulalongkorn University, Bangkok, Thailand

${ }^{4}$ Biostatistics Excellence Center, Department of Research Affairs, Chulalongkorn University, Bangkok, Thailand

${ }^{5}$ Department of Radiology, Faculty of Medicine, Chulalongkorn University, Bangkok, Thailand

${ }^{6}$ Center of Excellence in Clinical Virology, Faculty of Medicine, Chulalongkorn University, Bangkok, Thailand

Corresponding Author:

Piyawat Komolmit, $\mathrm{MD}, \mathrm{PhD}^{1,2,3}$

Rama 4, Pathumwan, Bangkok, 10330, Thailand

Email address: pkomolmit@yahoo.co.uk

\section{Abstract}

Background. Replacement of vitamin D (VD) among patients with chronic hepatitis C (CHC) before viral eradication has demonstrated a protective effect on serum markers associated with hepatic fibrogenesis. We therefore hypothesized that VD may facilitate further fibrosis amelioration following curative treatment with direct-acting antivirals (DAA).

Methods. This study was a randomized, double-blind, placebo-controlled trial conducted between February 2018 and August 2018. Patients with CHC and VD deficiency were randomized in a 1:1 ratio to either receive ergicalciferol or placebo over 6 weeks. Biochemical analysis indicators, including 25-hydroxyvitamin $\mathrm{D}(25(\mathrm{OH}) \mathrm{D})$, fibrogenic markers [(transforming growth factor beta 1 (TGF- $\beta 1$ ) and tissue inhibitors of matrix metalloproteinases 1 (TIMP-1)], and fibrolytic markers [matrix metalloproteinase 9 (MMP-9) and amino terminal type III procollagen peptide (P3NP)], were assessed at baseline and at 6 weeks. Serum 25(OH)D was analyzed by a chemiluminescence immunoassay. Serum hepatic fibrogenesis markers were measured using a quantitative sandwich enzyme-linked immunosorbent assay. 
40 Results. Seventy-five patients with $\mathrm{CHC}$ and VD deficiency were randomly assigned to VD

$41(n=37)$ and placebo $(n=38)$ groups. At the end of the study, the mean serum $25(\mathrm{OH}) \mathrm{D}$ level had

42 risen to a normal level in the VD group, but was still deficient in the placebo group (41.8 $\pm 9.1 \mathrm{vs}$.

$4318.1 \pm 4.6 \mathrm{ng} / \mathrm{mL}, \mathrm{p}<0.001)$. Upon restoration of the VD level, there were no significant mean

44 differences in the change from baseline for TGF- $\beta 1(-0.6 \mathrm{ng} / \mathrm{mL}$ ( $95 \%$ confidence interval

45 (95\%CI) -2.8 - 1.7), p=0.63), TIMP-1 (-5.5 ng/mL (95\%CI -26.4 - 15.3), p=0.60), MMP-9

46 (122.9 ng/mL (95\%CI -69.0 - 314.8), $\mathrm{p}=0.21)$, and P3NP (-0.1 ng/mL (95\%CI -2.4 - 2.2),

$47 \mathrm{p}=0.92)$ between the VD and placebo groups.

48 Conclusion. Short-term VD supplementation after DAA treatment in patients with CHC does

49 not improve serum fibrogenesis markers and may not expedite the residual liver fibrosis healing

50 process. Future studies are warranted to evaluate the long-term effect of VD supplementation on

51 hepatic fibrosis regression.

52

\section{Introduction}

54 Hepatic fibrogenesis is a complex, dynamic cellular process regulated by a balance between

55

56

57

58

59

60

61

62

63

64

65

66

67

68

69

70

71

72

73

74

75

76

77

78

fibrogenic and fibrolytic activities. Liver fibrogenic cytokines, such as transforming growth factor beta 1 (TGF- $\beta 1$ ) and tissue inhibitor of matrix metalloproteinase-1 (TIMP-1), initially activate the quiescent hepatic stellate cells (HSCs) after liver injury. This process consequently leads to a change in the fibrotic cascade and results in an excessive accumulation of extracellular matrix (ECM) within the liver parenchyma (Lee et al. 2015). Subsequently, the cellular healing process eventually occurs after the resolution of the injury. Matrix metalloproteinases (MMPs), which are important fibrolytic enzymes, play a pivotal role in matrix remodeling during the recovery phase. MMPs regulate collagen degradation, thereby facilitating liver fibrosis regression (Okazaki et al. 2000).

Hepatitis $\mathrm{C}$ virus (HCV) infection remains a major health-care problem worldwide, leading to high morbidity and mortality from cirrhosis and hepatocellular carcinoma (HCC) (Stanaway et al. 2016). Notably, the advent of direct-acting antiviral (DAA) therapy for HCV has transformed clinical practice and provided $>90 \%$ cure rate among patients with chronic hepatitis $\mathrm{C}$ (CHC) (European Association for the Study of the Liver. Electronic address \& European Association for the Study of the 2018). Amelioration of liver inflammation and improvement of hepatic synthetic function have been demonstrated during the course of treatment and shortly after the completion of DAA therapy (Charlton et al. 2015; Curry et al. 2015). Additionally, a remarkable reduction in liver stiffness has also been shown after successful HCV eradication (Dolmazashvili et al. 2017; Pan et al. 2018). However, a large number of patients with CHC still have substantial residual liver fibrosis after the viral cure, thereby remaining as an important concern in current clinical practice (Giannini et al. 2019; Singh et al. 2018). Recent studies have demonstrated that patients with CHC who still have advanced liver fibrosis and cirrhosis after a sustained virological response (SVR) remain at high risk of HCC (Su \& Ioannou 2019). Thus, guidelines recommend continuing an HCC

Peer) reviewing PDF | (2020:08:52141:1:2:NEW 12 Nov 2020) 
80

81

82

83

84

85

86

87

88

89

90

91

92

93

94

95

96

97

98

99

100

101

102

103

104

105

106

107

108

109

110

111

112

113

114

115

116

117

118

surveillance program for such patients (European Association for the Study of the Liver. Electronic address \& European Association for the Study of the 2018; Panel 2018).

Vitamin D (VD) deficiency/insufficiency is a global problem affecting approximately 1 billion people; its prevalence varies by age and ethnicity in different countries (Amrein et al. 2020). A number of studies have reported a high prevalence of VD deficiency in patients with chronic liver diseases, regardless of etiology (Arteh et al. 2010; Malham et al. 2011). Notably, $>60 \%$ of patients with CHC experience VD deficiency (Jin et al. 2018). Low serum VD levels could lead to negative liver-related consequences and liver fibrosis progression (Dadabhai et al. 2017; Kubesch et al. 2018). Moreover, in a recent clinical study, since the liver is an intermediate organ of VD metabolism, a high proportion of patients with CHC still have VD deficiency and insufficiency after successful HCV eradication (Backstedt et al. 2017; Sriphoosanaphan et al. 2020).

Growing experimental and clinical evidence has revealed an anti-fibrogenic effect of VD (Baur et al. 2012; Ding et al. 2013; Wahsh et al. 2016). Our previous study demonstrated a considerable improvement in serum fibrogenesis markers after VD restoration in patients with CHC before HCV treatment (Komolmit et al. 2017). This improvement could be due to the influence of VD on $\mathrm{HCV}$ replication, inflammation reduction, or the direct effect of VD on hepatic fibrogenesis. In this study, we aimed to further clarify the exact role of VD in hepatic fibrogenesis amelioration in patients with $\mathrm{CHC}$ who underwent curative treatment with DAA.

\section{Materials \& Methods}

\section{Study population and study design}

This randomized, double-blind, placebo-controlled study was conducted at King Chulalongkorn Memorial Hospital, which is a tertiary referral center and academic teaching hospital, in Bangkok, Thailand, from February 2018 to August 2018. All patients with CHC who achieved SVR within 1 year after DAA therapy in the hepatology clinic were assessed for eligibility. The inclusion criteria were as follows: age between 18 and 80 years, VD insufficiency/deficiency (defined as serum 25(OH)D level $<30 \mathrm{ng} / \mathrm{mL})$, and evidence of more than $\mathrm{F} 2$ liver fibrosis from either Fibroscan ${ }^{\circledR}$ (transient elastogram $\geq 7.1 \mathrm{kPa}$ (Castera et al. 2005)), ultrasound elastography ( $\geq 6.7$ $\mathrm{kPa}$ by 2D shear-wave elastography (Bende et al. 2017)), or magnetic resonance elastography ( $\geq 3.2 \mathrm{kPa}$ by two-dimensional gradient recall echo (Ichikawa et al. 2012)). Patients with a recent history of VD supplementation, evidence of chronic hepatitis B or human immunodeficiency virus infection, decompensated liver cirrhosis, autoimmune diseases, hepatocellular carcinoma, active infections from other pathogens, a history of steroid or immunosuppressive agent use, or a history of interferon treatment within 12 months, and those who were pregnant or lactating, were excluded.

Data were collected as previously described in Komolmit et al. (2017). Specifically, randomization was performed with a computer-generated allocation sequence. The eligible patients were randomly assigned to receive VD or placebo (1:1 allocation using a random block size of 4$)$. The 
119 process was performed by a research assistant who was not involved in the study. Randomization

120

121

122

123

124

125

126

127

128

129

130

131

132

133

134

135

136

137

138

139

140

141

142

143

144

145

146

147

148

149

150

151

152

153

154

155

156

157

codes were secured in sealed envelopes until all data entry was complete.

\section{Intervention}

Vitamin D2 (VD2, ergocalciferol) and the placebo were prepared in identical capsules of the same weight by the Department of Pharmacy at King Chulalongkorn Memorial Hospital. All investigators and patients were blinded to the type of medication used until the end of the study. Each capsule of VD2 contained 20,000 international units of ergocalciferol. The protocol for VD supplementation was based on the $25(\mathrm{OH}) \mathrm{D}$ level at baseline (Table 1), which has been previously demonstrated to effectively increase VD levels in patients with $\mathrm{CHC}$ within a 6-week period (Komolmit et al. 2017). All patients initially received ergocalciferol or placebo on the day of randomization.

Baseline clinical characteristics, HCV genotypes, liver enzymes, and fibrosis-4 (FIB-4) and aspartate aminotransferase to platelet ratio index (APRI) scores were assessed. Blood samples were collected at two time points (baseline and at the end of the 6-week follow-up) and were kept at $-70^{\circ} \mathrm{C}$ until analysis. All blood samples were simultaneously analyzed for TGF- $\beta 1$, TIMP-1, MMP-9, and amino terminal type III procollagen peptide (P3NP) levels at the end of the study. Pill counts and patient interviews were used to assess adherence to the prescribed medications. All participants were asked to refrain from outside-of-trial VD or multivitamin supplements and to maintain their normal activity. At the end of the study, patients who remained in a VD-insufficient state received VD supplementation as a standard of care.

\section{Outcomes and assessments}

The primary outcome was the effect of VD supplementation on serum markers associated with hepatic fibrogenesis, including TGF- $\beta 1$, TIMP- 1 , MMP-9, and P3NP, relative to the effect in the placebo group at the 6-week follow-up.

\section{Laboratory assessment}

\section{Measurement of 25(OH)D level}

Serum 25(OH)D levels, a functional indicator of VD status, were measured using the Liaison $25(\mathrm{OH})$ vitamin D total assay (DiaSorin, Saluggia, Italy); the measurement was performed on the LIAISON ${ }^{\circledR}$ chemiluminescence analyzer following the manufacturer's instructions. The final level is reported in ng/mL. According to the Endocrine Society Practice Guidelines (Holick et al. 2011), VD insufficiency/deficiency was defined as a $25(\mathrm{OH}) \mathrm{D}$ level $<30 \mathrm{ng} / \mathrm{mL}$. Specifically, serum 25(OH)D levels $<20 \mathrm{ng} / \mathrm{mL}$ and between $20-29 \mathrm{ng} / \mathrm{mL}$ were defined as VD deficiency and VD insufficiency, respectively.

\section{Measurement of TGF- $\beta 1$ level}


158 The serum levels of human activated TGF- $\beta 1$ were measured with a quantitative sandwich 159 enzyme-linked immunosorbent assay (ELISA) technique following the manufacturer's 160 instructions (Quantikine ${ }^{\circledR}$ ELISA, R\&D Systems, Minneapolis, MN, USA). Before the assay, the 161 latent TGF- $\beta 1$ contained in the patients' serum was activated to the immunoreactive form using 162 acid activation and neutralization. The results were calculated by reference to the standard curve.

163

164

165

166

167

168

169

170

171

172

173

174

175

176

177

178

179

180

181

182

183

184

185

186

187

188

189

190

191

192

193

194

195

196

197

\section{Measurement of TIMP-1 level}

The serum levels of human TIMP-1 were measured using the quantitative sandwich ELISA technique according to the manufacturer's instructions (Quantikine ${ }^{\circledR}$ ELISA). The results were calculated by reference to the standard curve.

\section{Measurement of MMP-9 level}

The serum levels of human MMP-9 protein were measured by a quantitative sandwich ELISA according to the manufacturer's instructions (Quantikine ${ }^{\circledR}$ ELISA). The results were calculated by reference to the standard curve.

\section{Measurement of P3NP level}

The serum levels of P3NP were measured via a quantitative sandwich ELISA technique according to the manufacturer's instructions (Cloud-Clone Corp., TX, USA). The results were calculated by reference to the standard curve.

\section{Sample size calculation}

Sample size calculations were based on data from our previous study on patients with CHC (Komolmit et al. 2017). Of the cytokines measured in both the present study and our previous study, we used the data of TGF- $\beta 1$ for the calculation, since it resulted in the largest sample size. The mean difference in the change in TGF- $\beta 1$ level from baseline to week 6 in the VD supplementation arm versus the placebo arm as a control was $81 \mathrm{pg} / \mathrm{mL}$, with a pooled standard deviation of 110 . Thus, enrolling 30 patients per group would give $80 \%$ power to detect a difference in TGF- $\beta 1$ change from baseline between treatment groups of this size or more, at a 2sided significance level of $5 \%$. We inflated the sample size to 37 per randomized arm to account for possible dropouts.

\section{Statistical analysis}

Baseline characteristics, including clinical and laboratory data, are presented as percentage or mean \pm standard deviation (SD). In the initial analyses, the baseline characteristics of the patients were compared using t-tests or chi-square tests. Categorical variables were analyzed using the chisquare test or Fisher's exact test, as appropriate. For the primary study outcome of fibrogenesis marker changes, we used the independent $t$-test to evaluate mean differences and $95 \%$ confidence interval $(95 \% \mathrm{CI})$ in the change from baseline to week 6 between the VD and the placebo groups. As a sensitivity analysis, to ensure that outliers did not exert an undue influence on the obtained 
198

199

200

201

202

203

204

205

206

207

208

209

210

211

212

213

214

215

216

217

218

219

220

221

222

223

224

225

226

227

228

229

230

231

232

233

234

235

236

237

between-arm estimates, we summarized the data as the median and $25^{\text {th }}$ and $75^{\text {th }}$ percentile levels, and used quantile regression to compare the median serum level changes between randomized arms. Statistical analyses were performed with Stata 16.1 (Statacorp, College Station, TX, USA).

\section{Ethical approval}

This study was reviewed and approved by the Ethics Committee and Institutional Review Board (IRB) at Chulalongkorn University, Bangkok, Thailand, and was performed in accordance with the Declaration of Helsinki (1989) of the World Medical Association (IRB number: 707/60). Moreover, this trial was registered with the Thai Clinical Trials Registry (TCTR) based on the World Health Organization criteria on 22 November 2017 (TCTR20171206003). Prior to participation, all patients enrolled in this study provided written informed consent for participation, as well as for publication.

\section{Results}

\section{Patient characteristics}

Between February 2018 and August 2018, 80 patients with CHC who achieved SVR after DAA treatment were screened for eligibility. Five patients were excluded from the study (Fig 1). A total of 75 patients were finally included and randomly assigned to the VD group $(n=37)$ or the placebo group $(n=38)$. Mean age was $60.4 \pm 7.8$ years, patients were mostly female $(n=45,60 \%)$, and a majority of the participants had cirrhosis $(n=45,60 \%)$. As shown in Table 2, baseline characteristics between the groups were well balanced. No significant difference in any of the biochemical parameters and degree of liver fibrosis, as measured by FIB-4 and APRI scores, was found between the groups.

\section{Changes in VD levels}

Mean baseline serum 25(OH)D level was $17.2 \pm 4.8 \mathrm{ng} / \mathrm{mL}$ and $16.6 \pm 4.1 \mathrm{ng} / \mathrm{mL}$ in the VD and placebo groups, respectively. At the 6-week follow-up, the mean $25(\mathrm{OH}) \mathrm{D}$ level in the VD group increased to a normal level $(41.8 \pm 9.1 \mathrm{ng} / \mathrm{mL})$, whereas a slight increase was observed in the placebo group (18.1 $\pm 4.6 \mathrm{ng} / \mathrm{mL}$ ) (Fig 2). The mean difference in $25(\mathrm{OH}) \mathrm{D}$ change from baseline to week 6 reflected a significantly greater change in the VD group than in the placebo group (23.1 $\mathrm{ng} / \mathrm{mL}(95 \% \mathrm{CI} 19.7-26.4), \mathrm{p}<0.001)$.

Of note, three patients (8.1\%) in the VD group still had a serum $25(\mathrm{OH}) \mathrm{D}$ level $<30 \mathrm{ng} / \mathrm{mL}$ at 6 weeks after VD replacement; the $25(\mathrm{OH}) \mathrm{D}$ levels in two patients changed from an initial deficient state to an insufficient state after VD supplementation (absolute VD increase of 18.3 and 18.4 $\mathrm{ng} / \mathrm{mL}$, respectively), while the remaining patient had a slightly increased VD level (from 21.8 $\mathrm{ng} / \mathrm{mL}$ at baseline to $23.5 \mathrm{ng} / \mathrm{mL}$ ) after VD replacement. All participants in the placebo group still had VD insufficiency/deficiency. All unused pills were returned at the last follow-up, and no patient reported missing any medications. 


\section{Changes in serum hepatic fibrogenesis markers}

239 Mean and median differences in serum marker changes from baseline to 6 weeks are shown in 240 Tables 3 and 4, respectively, and in Figure 3. Serum TGF- $\beta 1$ levels slightly increased from $24116.3 \pm 6.6 \mathrm{ng} / \mathrm{mL}$ at baseline to $16.8 \pm 7.6 \mathrm{ng} / \mathrm{mL}$ at 6 weeks in the VD group, and increased from $24214.3 \pm 8.3$ to $15.4 \pm 6.8 \mathrm{ng} / \mathrm{mL}$ in the placebo group. However, there was no significant difference in 243 the mean change from baseline between the VD and placebo groups $(-0.6 \mathrm{ng} / \mathrm{mL}(95 \% \mathrm{CI}-2.8-$ 244 1.7), $\mathrm{p}=0.63)$.

245

Similarly, mean serum TIMP-1 levels in the VD group slightly increased from $236.9 \pm 50.0 \mathrm{ng} / \mathrm{mL}$ at baseline to $244.0 \pm 66.0 \mathrm{ng} / \mathrm{mL}$ at 6 weeks. In the placebo group, mean serum TIMP-1 levels slightly increased from $231.9 \pm 50.3 \mathrm{ng} / \mathrm{mL}$ at baseline to $244.5 \pm 63.6 \mathrm{ng} / \mathrm{mL}$ at 6 weeks. There was no significant difference in the mean TIMP-1 change from baseline to 6 weeks between the VD and placebo groups $(-5.5 \mathrm{ng} / \mathrm{mL}(95 \% \mathrm{CI}-26.4-15.3), \mathrm{p}=0.60)$.

251

252

Regarding fibrolytic markers, mean MMP-9 levels showed an increasing trend in the VD group 253 $(576.2 \pm 296.2 \mathrm{ng} / \mathrm{mL}$ at baseline and $684.3 \pm 423.5 \mathrm{ng} / \mathrm{mL}$ at 6 weeks); median levels showed a consistent pattern. In contrast, mean MMP-9 levels in the placebo group were approximately the same at baseline and week 6 , but the median levels increased. There was no significant difference in the mean change from baseline at week 6 between the VD and placebo groups $(122.9 \mathrm{ng} / \mathrm{mL}$ $(95 \%$ CI $-69.0-314.8), p=0.21)$.

Mean P3NP levels slightly decreased from the baseline in both groups. There was no significant difference in the mean P3NP change score from baseline to week 6 between the VD and placebo groups $(-0.1 \mathrm{ng} / \mathrm{mL}(95 \% \mathrm{CI}-2.4-2.2), \mathrm{p}=0.92)$.

262

263

\section{Sensitivity analysis}

264

We conducted quantile regression, using the median as another measure of the central tendency, to assess whether extreme outliers in the dataset had a strong influence on the observed associations. In both VD and placebo groups, the median, $25^{\text {th }}$ and $75^{\text {th }}$ percentile values of each marker were very similar at baseline and week 6 visits (Fig. 3, Table 4). The differences in the mean and median changes in marker concentrations from baseline to week 6 between randomized arms were of similar magnitude and direction, with the exception of MMP-9. For this latter marker, the mean change was greater, but the median change was smaller, in the VD group than in the

272 placebo group. However, neither result was statistically significant, and the $95 \% \mathrm{CI}$ around both 273

274 Subgroup analysis

275 A subgroup analysis was performed according to the severity of VD deficiency/insufficiency, 276 which showed no significant changes in serum hepatic fibrogenesis markers in both groups. 
277 Additional subgroup analyses based on sex, cirrhosis, liver fibrosis severity, and a 25(OH)D level $278<10 \mathrm{ng} / \mathrm{ml}$ at baseline also revealed similar results (Table S1 and S2).

279

\section{Discussion}

281

282

283

284

285

286

287

288

289

290

291

292

293

294

295

296

297

298

299

300

301

302

303

304

305

306

307

308

309

310

311

312

313

314

315

In this randomized, double-blind, placebo-controlled study, 6-week VD supplementation in patients with $\mathrm{CHC}$ after $\mathrm{HCV}$ eradication by DAA did not help attenuate liver fibrosis as assessed by fibrogenesis markers. Additionally, the effect of VD supplementation did not vary according to baseline serum 25(OH)D levels and liver fibrosis severity.

Activation of HSCs to myofibroblast-like cells by TGF- $\beta 1$ results in fibrillary component accumulation, which leads to progressive liver fibrosis (Lee et al. 2015). TGF- $\beta 1$ also regulates TIMP-1 production, which subsequently inhibits the breakdown of excessive ECM (Flisiak et al. 2005). In contrast, a shift toward fibrolytic activity results in the reversal of liver fibrosis. MMPs function as the main enzymes responsible for fibrillary matrix cleavage (Wynn 2007). P3NP is a breakdown peptide produced during the healing process, and is widely used as a marker for hepatic fibrolysis. A decline in P3NP levels correlates with an increase in cellular fibrosis degradation and indicates liver fibrosis regression (Nielsen et al. 2015). Based on their involvement in hepatic fibrogenesis, these cellular cytokines and enzymes have been used as markers for an indirect assessment of hepatic fibrogenesis (Komolmit et al. 2017; Liu et al. 2012)

Apart from its classical action on calcium metabolism, VD is involved in various cellular regulatory processes. Immunomodulatory, anti-inflammatory, and anti-fibrotic properties of VD have been reported in numerous studies. VD plays a crucial role in the functioning of the innate and adaptive immune systems (Aranow 2011; Holick 2007). Further, VD has also been demonstrated as an innate antiviral agent; it exerts an inhibitory effect on HCV replication in human cells (Gal-Tanamy et al. 2011). Regarding the association of VD and hepatic fibrogenesis, VD receptor (VDR) mRNA in HSCs is upregulated in response to TGF- $\beta 1$ (Beilfuss et al. 2015). A study by Ding et al. showed spontaneous liver cirrhosis in VDR knockout mice, which was mediated by the TGF- $\beta$ /VDR/SMAD signaling circuit (Ding et al. 2013). In addition, 1,25(OH)D stimulated VDR expression in primary rat HSCs and suppressed TIMP-1 mRNA expression, resulting in an improvement in fibrotic score in thioacetamide-induced liver fibrosis (Abramovitch et al. 2011). Furthermore, a synthetic VD analogue, calcipotriol, has been found to prevent liver cirrhosis in a mouse model (Wahsh et al. 2016). In a human study, Beilfuss et al. demonstrated the role of VD in liver fibrogenesis via the crosstalk between VD and the TGF- $\beta 1$ signaling pathway. With VD supplementation, a reduced fibrogenic response in human HSCs was observed (Beilfuss et al. 2015). Based on the aforementioned evidence, at least three main properties of VD that could influence the fibrinolytic state can be postulated: anti-viral (i.e., suppression of viral replication), anti-inflammatory, and anti-fibrotic properties. 
316 In our previous study, restoration of VD levels in patients with $\mathrm{CHC}$ resulted in dynamic shifts of 317 serum fibrosis markers toward anti-fibrotic activity. The levels of pro-fibrotic cytokines (i.e. TGF$318 \beta 1$ and TIMP-1) significantly decreased in the VD supplementation group, whereas the levels of 319 anti-fibrotic enzymes (i.e. MMP-2 and MMP-9) were significantly higher in the VD

320

321

322

323

324

325

326

327

328

329

330

331

332

333

334

335

336

337

338

339

340

341

342

343

344

345

346

347

348

349

350

351

352

353

354

355 supplementation group than in the placebo group (Komolmit et al. 2017). This evidence highlights and supports the protective role of VD in the hepatic fibrogenesis process. In our current study, we aimed to explore the effect of VD replacement after curative HCV therapy in order to ascertain whether VD mainly facilitates fibrolytic processes by halting fibrogenesis, not by its effect on HCV replication or inflammation. Based on our results, VD restoration after HCV eradication did not cause significant changes in serum markers associated with hepatic fibrogenesis. Hence, one could assume that VD, at the clinical level, might not help facilitate hepatic fibrolysis. In addition, the effect of VD on the improvement in fibrogenesis markers, as shown in our previous study, might not be directly achieved via the intrinsic fibrogenesis cascades, as observed in several experimental results. Thus, apart from HCV eradication and the resolution of liver inflammation, VD restoration after DAA treatment may not provide any further benefit in the reversal of hepatic fibrogenesis. This seems to suggest that VD might regulate and influence hepatic fibrogenesis through its immunomodulatory rather than its anti-fibrotic property. While VD might have a role in hepatic fibrosis regulation, its contribution is not strong enough to affect the associated serum markers. Investigation on changes in local tissue levels to elucidate this observation may be warranted.

The baseline TGF- $\beta 1$ levels in the current cohort could be another possible explanation for the major difference in results between our previous and current studies. Unlike our previous study, the baseline TGF- $\beta 1$ levels were similar to those observed in healthy volunteers (Flisiak et al. 2005; Grainger et al. 2000), and were consistent with the levels in successfully treated patients with $\mathrm{CHC}$ in studies conducted in the interferon era (Flisiak et al. 2005; Kotsiri et al. 2016). Given the normalized baseline serum TGF- $\beta 1$ levels, a large number of participants would be needed to detect differences in the outcome of interest. It is more likely that, at this stage in clinical trials, an investigation into the hepatic tissue expression levels of each marker would be appropriate to further test our hypothesis. However, in the era of DAA therapy for $\mathrm{CHC}$, a paired liver biopsy has ethical implications.

In contrast to TGF- $\beta 1$ levels, the MMP-9 and P3NP levels at baseline were higher than those in healthy population (Latronico et al. 2016; Teare et al. 1993). A closer analysis of the hepatic fibrolytic processes revealed a trend towards fibrosis degradation as evidenced by the changes in MMP-9 and P3NP levels; however, the changes did not reach statistical significance.

Apart from VD levels, genetic variation in the $V D R$ gene might be one of the factors with an influence on the study findings. Since $V D R$ polymorphism has been shown to be associated with liver fibrosis and potentially determines the VD response (Baur et al. 2012; Estrabaud et al. 2012), 
356 the negative results of the current study might be partly due to $V D R$ genetic variation. However,

357

358

359

360

361

362

363

364

365

366

367

368

369

370

371

372

373

374

375

376

377

378

379

380

381

382

383

384

385

386

387

388

389

390

391

392

393

394

this assumption cannot be confirmed in the current clinical setting.

To the best of our knowledge, this is the first study to determine the effect of VD on liver fibrosis in patients with $\mathrm{CHC}$ after DAA treatment. We presented some additional evidence on the influence of VD on hepatic fibrogenesis. Nevertheless, this study has some limitations. First, several factors, such as diet, sunlight exposure, and supplementary products, could affect the measured serum VD levels. To minimize the possible influence of these factors and other potential biases, we employed a double-blind, placebo-controlled study design. Moreover, the participants were advised to maintain their usual activities of daily living and avoid any supplements during the study period. Second, histological evidence in the liver parenchyma would ideally be a gold standard to evaluate liver fibrosis. However, paired liver biopsy is an invasive procedure, and thus, is not free of risk. Owing to ethical and practical considerations, we decided to employ a noninvasive approach using surrogate serum markers to evaluate fibrogenesis. Lastly, we selected a 6-week time point because, in our previous study, VD levels were normalized in most of the patients by VD supplementation within this time period. As hepatic fibrogenesis is highly dynamic, and the half-lives of serum fibrogenesis cytokines and enzymes are relatively short, with spans of hours and days, we believe that a local immunological change would be initially demonstrated within this time period. However, since the reversal of hepatic fibrogenesis could take months or years to show a clinical benefit, a short follow-up period may be inadequate for detecting any significant difference. Hence, future long-term studies are needed to further our understanding.

\section{Conclusions}

Short-term VD replacement after HCV eradication by DAA did not improve serum hepatic fibrogenesis marker levels and, thus, might not clinically facilitate the amelioration of residual liver fibrosis. Nevertheless, further investigation to determine whether a higher dose (VD derivative) for a longer period could potentially help ameliorate liver fibrosis is warranted.

\section{Acknowledgements}

We would like to express our gratitude to the staff of the Division of Gastroenterology, Department of Medicine, Center of Excellence in Liver Diseases, King Chulalongkorn Memorial Hospital, and Center of Excellence in Clinical Virology, Faculty of Medicine, Chulalongkorn University for their technical assistance and clinical support.

\section{References}

Abramovitch S, Dahan-Bachar L, Sharvit E, Weisman Y, Ben Tov A, Brazowski E, and Reif S. 2011. Vitamin D inhibits proliferation and profibrotic marker expression in hepatic stellate cells and decreases thioacetamide-induced liver fibrosis in rats. Gut 60:17281737. 10.1136/gut.2010.234666 
395

396

397

398

399

400

401

402

403

404

405

406

407

408

409

410

411

412

413

414

415

416

417

418

419

420

421

422

423

424

425

426

427

428

429

430

431

432

433

Amrein K, Scherkl M, Hoffmann M, Neuwersch-Sommeregger S, Kostenberger M, Tmava Berisha A, Martucci G, Pilz S, and Malle O. 2020. Vitamin D deficiency 2.0: an update on the current status worldwide. Eur J Clin Nutr. 10.1038/s41430-020-0558-y

Aranow C. 2011. Vitamin D and the immune system. J Investig Med 59:881-886. 10.2310/JIM.0b013e31821b8755

Arteh J, Narra S, and Nair S. 2010. Prevalence of vitamin D deficiency in chronic liver disease. Dig Dis Sci 55:2624-2628. 10.1007/s10620-009-1069-9

Backstedt D, Pedersen M, Choi M, and Seetharam A. 2017. 25-Vitamin D levels in chronic hepatitis $\mathrm{C}$ infection: association with cirrhosis and sustained virologic response. Ann Gastroenterol 30:344-348. 10.20524/aog.2017.0120

Baur K, Mertens JC, Schmitt J, Iwata R, Stieger B, Eloranta JJ, Frei P, Stickel F, Dill MT, Seifert B, Ferrari HA, von Eckardstein A, Bochud PY, Mullhaupt B, and Geier A. 2012. Combined effect of 25-OH vitamin D plasma levels and genetic vitamin D receptor (NR 1I1) variants on fibrosis progression rate in HCV patients. Liver Int 32:635-643. 10.1111/j.1478-3231.2011.02674.x

Beilfuss A, Sowa JP, Sydor S, Beste M, Bechmann LP, Schlattjan M, Syn WK, Wedemeyer I, Mathe Z, Jochum C, Gerken G, Gieseler RK, and Canbay A. 2015. Vitamin D counteracts fibrogenic TGF-beta signalling in human hepatic stellate cells both receptordependently and independently. Gut 64:791-799. 10.1136/gutjnl-2014-307024

Bende F, Sporea I, Sirli R, Popescu A, Mare R, Miutescu B, Lupusoru R, Moga T, and Pienar C. 2017. Performance of 2D-SWE.GE for predicting different stages of liver fibrosis, using Transient Elastography as the reference method. Med Ultrason 19:143-149. 10.11152/mu-910

Castera L, Vergniol J, Foucher J, Le Bail B, Chanteloup E, Haaser M, Darriet M, Couzigou P, and De Ledinghen V. 2005. Prospective comparison of transient elastography, Fibrotest, APRI, and liver biopsy for the assessment of fibrosis in chronic hepatitis $\mathrm{C}$. Gastroenterology 128:343-350. 10.1053/j.gastro.2004.11.018

Charlton M, Everson GT, Flamm SL, Kumar P, Landis C, Brown RS, Jr., Fried MW, Terrault NA, O'Leary JG, Vargas HE, Kuo A, Schiff E, Sulkowski MS, Gilroy R, Watt KD, Brown K, Kwo P, Pungpapong S, Korenblat KM, Muir AJ, Teperman L, Fontana RJ, Denning J, Arterburn S, Dvory-Sobol H, Brandt-Sarif T, Pang PS, McHutchison JG, Reddy KR, Afdhal N, and Investigators S-. 2015. Ledipasvir and Sofosbuvir Plus Ribavirin for Treatment of HCV Infection in Patients With Advanced Liver Disease. Gastroenterology 149:649-659. 10.1053/j.gastro.2015.05.010

Curry MP, O'Leary JG, Bzowej N, Muir AJ, Korenblat KM, Fenkel JM, Reddy KR, Lawitz E, Flamm SL, Schiano T, Teperman L, Fontana R, Schiff E, Fried M, Doehle B, An D, McNally J, Osinusi A, Brainard DM, McHutchison JG, Brown RS, Jr., Charlton M, and Investigators A-. 2015. Sofosbuvir and Velpatasvir for HCV in Patients with Decompensated Cirrhosis. N Engl J Med 373:2618-2628. 10.1056/NEJMoa1512614 
434 Dadabhai AS, Saberi B, Lobner K, Shinohara RT, and Mullin GE. 2017. Influence of vitamin D

435

436

437

438

439

440

441

442

443

444

445

446

447

448

449

450

451

452

453

454

455

456

457

458

459

460

461

462

463

464

465

466

467

468

469

470

471

472

473 on liver fibrosis in chronic hepatitis C: A systematic review and meta-analysis of the pooled clinical trials data. World J Hepatol 9:278-287. 10.4254/wjh.v9.i5.278

Ding N, Yu RT, Subramaniam N, Sherman MH, Wilson C, Rao R, Leblanc M, Coulter S, He M, Scott C, Lau SL, Atkins AR, Barish GD, Gunton JE, Liddle C, Downes M, and Evans RM. 2013. A vitamin D receptor/SMAD genomic circuit gates hepatic fibrotic response. Cell 153:601-613. 10.1016/j.cell.2013.03.028

Dolmazashvili E, Abutidze A, Chkhartishvili N, Karchava M, Sharvadze L, and Tsertsvadze T. 2017. Regression of liver fibrosis over a 24-week period after completing direct-acting antiviral therapy in patients with chronic hepatitis $\mathrm{C}$ receiving care within the national hepatitis $\mathrm{C}$ elimination program in Georgia: results of hepatology clinic HEPA experience. Eur J Gastroenterol Hepatol 29:1223-1230.

10.1097/meg.0000000000000964

Estrabaud E, Vidaud M, Marcellin P, and Asselah T. 2012. Genomics and HCV infection: progression of fibrosis and treatment response. J Hepatol 57:1110-1125. 10.1016/j.jhep.2012.05.016

European Association for the Study of the Liver. Electronic address eee, and European Association for the Study of the L. 2018. EASL Recommendations on Treatment of Hepatitis C 2018. J Hepatol 69:461-511. 10.1016/j.jhep.2018.03.026

Flisiak R, Jaroszewicz J, Lapinski TW, Flisiak I, and Prokopowiczi D. 2005. Effect of pegylated interferon alpha $2 \mathrm{~b}$ plus ribavirin treatment on plasma transforming growth factor-beta1, metalloproteinase-1, and tissue metalloproteinase inhibitor-1 in patients with chronic hepatitis C. World J Gastroenterol 11:6833-6838. 10.3748/wjg.v11.i43.6833

Gal-Tanamy M, Bachmetov L, Ravid A, Koren R, Erman A, Tur-Kaspa R, and Zemel R. 2011. Vitamin D: an innate antiviral agent suppressing hepatitis $\mathrm{C}$ virus in human hepatocytes. Hepatology 54:1570-1579. 10.1002/hep.24575

Giannini EG, Crespi M, Demarzo M, Bodini G, Furnari M, Marabotto E, Torre F, Zentilin P, and Savarino V. 2019. Improvement in hepatitis C virus patients with advanced, compensated liver disease after sustained virological response to direct acting antivirals. Eur J Clin Invest 49:e13056. 10.1111/eci.13056

Grainger DJ, Mosedale DE, and Metcalfe JC. 2000. TGF-beta in blood: a complex problem. Cytokine Growth Factor Rev 11:133-145. 10.1016/s1359-6101(99)00037-4

Holick MF. 2007. Vitamin D deficiency. N Engl J Med 357:266-281. 10.1056/NEJMra070553

Holick MF, Binkley NC, Bischoff-Ferrari HA, Gordon CM, Hanley DA, Heaney RP, Murad $\mathrm{MH}$, and Weaver CM. 2011. Evaluation, treatment, and prevention of vitamin D deficiency: an Endocrine Society clinical practice guideline. J Clin Endocrinol Metab 96:1911-1930. 10.1210/jc.2011-0385

Ichikawa S, Motosugi U, Ichikawa T, Sano K, Morisaka H, Enomoto N, Matsuda M, Fujii H, and Araki T. 2012. Magnetic resonance elastography for staging liver fibrosis in chronic hepatitis C. Magn Reson Med Sci 11:291-297. 10.2463/mrms.11.291

Peer] reviewing PDF | (2020:08:52141:1:2:NEW 12 Nov 2020) 
474 Jin CN, Chen JD, and Sheng JF. 2018. Vitamin D deficiency in hepatitis C virus infection: what

475

476

477

478

479

480

481

482

483

484

485

486

487

488

489

490

491

492

493

494

495

496

497

498

499

500

501

502

503

504

505

506

507

508

509

510

511

512

513

is old? what is new? Eur J Gastroenterol Hepatol 30:741-746.

10.1097/MEG.0000000000001134

Komolmit P, Kimtrakool S, Suksawatamnuay S, Thanapirom K, Chattrasophon K, Thaimai P, Chirathaworn C, and Poovorawan Y. 2017. Vitamin D supplementation improves serum markers associated with hepatic fibrogenesis in chronic hepatitis $\mathrm{C}$ patients: A randomized, double-blind, placebo-controlled study. Sci Rep 7:8905.

Kotsiri I, Hadziyannis E, Georgiou A, Papageorgiou MV, Vlachogiannakos I, and Papatheodoridis G. 2016. Changes in serum transforming growth factor-betal levels in chronic hepatitis C patients under antiviral therapy. Ann Gastroenterol 29:79-84.

Kubesch A, Quenstedt L, Saleh M, Ruschenbaum S, Schwarzkopf K, Martinez Y, Welsch C, Zeuzem S, Welzel TM, and Lange CM. 2018. Vitamin D deficiency is associated with hepatic decompensation and inflammation in patients with liver cirrhosis: A prospective cohort study. PLoS One 13:e0207162. 10.1371/journal.pone.0207162

Latronico T, Mascia C, Pati I, Zuccala P, Mengoni F, Marocco R, Tieghi T, Belvisi V, Lichtner M, Vullo V, Mastroianni CM, and Liuzzi GM. 2016. Liver Fibrosis in HCV Monoinfected and HIV/HCV Coinfected Patients: Dysregulation of Matrix Metalloproteinases (MMPs) and Their Tissue Inhibitors TIMPs and Effect of HCV Protease Inhibitors. Int J Mol Sci 17:455. 10.3390/ijms17040455

Lee YA, Wallace MC, and Friedman SL. 2015. Pathobiology of liver fibrosis: a translational success story. Gut 64:830-841. 10.1136/gutjnl-2014-306842

Liu T, Wang X, Karsdal MA, Leeming DJ, and Genovese F. 2012. Molecular serum markers of liver fibrosis. Biomark Insights 7:105-117. 10.4137/BMI.S10009

Malham M, Jorgensen SP, Ott P, Agnholt J, Vilstrup H, Borre M, and Dahlerup JF. 2011. Vitamin D deficiency in cirrhosis relates to liver dysfunction rather than aetiology. World J Gastroenterol 17:922-925. 10.3748/wjg.v17.i7.922

Nielsen MJ, Veidal SS, Karsdal MA, Orsnes-Leeming DJ, Vainer B, Gardner SD, Hamatake R, Goodman ZD, Schuppan D, and Patel K. 2015. Plasma Pro-C3 (N-terminal type III collagen propeptide) predicts fibrosis progression in patients with chronic hepatitis $\mathrm{C}$. Liver Int 35:429-437. 10.1111/liv.12700

Okazaki I, Watanabe T, Hozawa S, Arai M, and Maruyama K. 2000. Molecular mechanism of the reversibility of hepatic fibrosis: with special reference to the role of matrix metalloproteinases. J Gastroenterol Hepatol 15 Suppl:D26-32. 10.1046/j.14401746.2000.02185.x

Pan JJ, Bao F, Du E, Skillin C, Frenette CT, Waalen J, Alaparthi L, Goodman ZD, and Pockros PJ. 2018. Morphometry Confirms Fibrosis Regression From Sustained Virologic Response to Direct-Acting Antivirals for Hepatitis C. Hepatol Commun 2:1320-1330.

Panel A-IHG. 2018. Hepatitis C Guidance 2018 Update: AASLD-IDSA Recommendations for Testing, Managing, and Treating Hepatitis C Virus Infection. Clin Infect Dis 67:14771492. 10.1093/cid/ciy585

Peer] reviewing PDF | (2020:08:52141:1:2:NEW 12 Nov 2020) 
514 Singh S, Facciorusso A, Loomba R, and Falck-Ytter YT. 2018. Magnitude and Kinetics of

515

516

517

518

519

520

521

522

523

524

525

526

527

528

529

530

531

532

533

534

535

536

537

538

539

540

541

542
Decrease in Liver Stiffness After Antiviral Therapy in Patients With Chronic Hepatitis C: A Systematic Review and Meta-analysis. Clin Gastroenterol Hepatol 16:27-38 e24. 10.1016/j.cgh.2017.04.038

Sriphoosanaphan S, Thanapirom K, Suksawatamnuay S, Thaimai P, Sittisomwong S, Sonsiri K, Srisoonthorn N, Teeratorn N, Tanpowpong N, Chaopathomkul B, Treeprasertsuk S, Poovorawan Y, and Komolmit P. 2020. Changes in hepatic fibrosis and vitamin D levels after viral hepatitis $\mathrm{C}$ eradication using direct-acting antiviral therapy. $B M C$ Gastroenterol 20:346. 10.1186/s12876-020-01485-8

Stanaway JD, Flaxman AD, Naghavi M, Fitzmaurice C, Vos T, Abubakar I, Abu-Raddad LJ, Assadi R, Bhala N, Cowie B, Forouzanfour MH, Groeger J, Mohd Hanafiah K, Jacobsen KH, James SL, MacLachlan J, Malekzadeh R, Martin NK, Mokdad AA, Mokdad AH, Murray CJ, Plass D, Rana S, Rein DB, Richardus JH, Sanabria J, Saylan M, Shahraz S, So S, Vlassov VV, Weiderpass E, Wiersma ST, Younis M, Yu C, El Sayed Zaki M, and Cooke GS. 2016. The global burden of viral hepatitis from 1990 to 2013: findings from the Global Burden of Disease Study 2013. Lancet 388:1081-1088. 10.1016/s01406736(16)30579-7

Su F, and Ioannou GN. 2019. Hepatocellular Carcinoma Risk After Direct-Acting Antiviral Therapy. Clin Liver Dis (Hoboken) 13:6-12. 10.1002/cld.781

Teare JP, Sherman D, Greenfield SM, Simpson J, Bray G, Catterall AP, Murray-Lyon IM, Peters TJ, Williams R, and Thompson RP. 1993. Comparison of serum procollagen III peptide concentrations and PGA index for assessment of hepatic fibrosis. Lancet 342:895-898. 10.1016/0140-6736(93)91946-j

Wahsh E, Abu-Elsaad N, El-Karef A, and Ibrahim T. 2016. The vitamin D receptor agonist, calcipotriol, modulates fibrogenic pathways mitigating liver fibrosis in-vivo: An experimental study. Eur J Pharmacol 789:362-369. 10.1016/j.ejphar.2016.07.052

Wynn TA. 2007. Common and unique mechanisms regulate fibrosis in various fibroproliferative diseases. J Clin Invest 117:524-529. 10.1172/jci31487 
Table $\mathbf{1}$ (on next page)

Protocol for VD supplementation 
1 Table 1. Protocol for VD supplementation

2

\begin{tabular}{|l|l|l|l|l|}
\hline Diagnosis & $\begin{array}{l}\mathbf{2 5}(\mathbf{O H}) \mathbf{D} \text { level } \\
\mathbf{( n g / m L )}\end{array}$ & $\begin{array}{l}\text { Replacement } \\
\text { (IU/week) }\end{array}$ & $\begin{array}{l}\text { Ergocalciferol } \\
\mathbf{2 0 , 0 0 0} \text { IU/tab }\end{array}$ & Duration \\
\hline Insufficiency & $20-30$ & 60,000 & $\begin{array}{l}\text { 2 tabs Monday } \\
\text { and 1 tab Friday }\end{array}$ & 6 weeks \\
\hline Deficiency & $10-20$ & 80,000 & $\begin{array}{l}\text { 2 tabs Monday } \\
\text { and 2 tabs Friday }\end{array}$ & 6 weeks \\
\hline Severe deficiency & $<10$ & 100,000 & $\begin{array}{l}\text { 3 tabs Monday } \\
\text { and 2 tabs Friday }\end{array}$ & 6 weeks \\
\hline
\end{tabular}

3

4 * VD: vitamin D; 25(OH)D: 25-hydroxyvitamin D; IU: international unit 
Table 2 (on next page)

Baseline characteristics 
2

Table 2. Baseline characteristics

\begin{tabular}{|c|c|c|}
\hline & VD group $(n=37)$ & Placebo $(n=38)$ \\
\hline Age (years) & $60.9 \pm 7.8$ & $59.4 \pm 8.0$ \\
\hline Sex, male & $16(43.2 \%)$ & $14(36.8 \%)$ \\
\hline Body mass index $\left(\mathrm{kg} / \mathrm{m}^{2}\right)$ & $25.3 \pm 4.3$ & $24.3 \pm 4.1$ \\
\hline $\begin{array}{l}\mathrm{HCV} \text { viral load before treatment } \\
(\log \mathrm{IU} / \mathrm{mL})\end{array}$ & $5.9 \pm 0.9$ & $5.5 \pm 1.4$ \\
\hline Genotype (n) & & \\
\hline 1 & 19 & 18 \\
\hline 3 & 17 & 17 \\
\hline 6 & 1 & 3 \\
\hline Cirrhosis & $21(56.8 \%)$ & $24(63.2 \%)$ \\
\hline AST (U/L) & $29.6 \pm 16.0$ & $28.9 \pm 10.9$ \\
\hline ALT (U/L) & $23.5 \pm 11.0$ & $23.7 \pm 10.0$ \\
\hline DAA regimen & & \\
\hline SOF/DAC & 11 & 4 \\
\hline SOF/LED & 1 & 3 \\
\hline SOF/VEL & 0 & 0 \\
\hline $\mathrm{SOF} / \mathrm{DAC} / \mathrm{RBV}$ & 23 & 23 \\
\hline $\mathrm{SOF} / \mathrm{LED} / \mathrm{RBV}$ & 1 & 7 \\
\hline SOF/VEL/RBV & 1 & 1 \\
\hline Fibrosis 4 score (FIB-4) & $2.8 \pm 2.1$ & $3.4 \pm 2.8$ \\
\hline AST to platelet ratio index (APRI) & $0.6 \pm 0.5$ & $0.7 \pm 0.6$ \\
\hline 25(OH)D level (ng/mL) & $17.2 \pm 4.8$ & $16.6 \pm 4.1$ \\
\hline TGF- $\beta 1$ level (ng/mL) & $16.3 \pm 6.6$ & $14.3 \pm 8.3$ \\
\hline TIMP-1 level (ng/mL) & $236.9 \pm 50.0$ & $231.9 \pm 50.3$ \\
\hline MMP-9 level (ng/mL) & $576.2 \pm 296.2$ & $570.1 \pm 477.7$ \\
\hline P3NP level (ng/mL) & $28.6 \pm 5.7$ & $28.0 \pm 4.3$ \\
\hline
\end{tabular}

3

4

5

6

7

8

*VD: vitamin D; HCV: Hepatitis C virus; IU: international unit; AST: aspartate aminotransferase; ALT: alanine aminotransferase; DAA: direct-acting antiviral; SOF: sofosbuvir; DAC: daclatasvir; LED: ledipasvir; VEL: velpatasvir; RBV: ribavirin; 25(OH)D: 25-hydroxyvitamin D; TGF- $\beta 1$ : transforming growth factor beta 1; TIMP-1: tissue inhibitor of matrix metalloproteinase-1; MMP-9: matrix metalloproteinase 9; P3NP: amino terminal type III procollagen peptide 


\section{Table 3 (on next page)}

Serum biochemical markers levels at baseline and 6 weeks of follow-up, and the mean difference $(95 \% \mathrm{Cl})$ in serum marker change from baseline to 6 weeks in the VD versus the placebo arm as a reference 
1 Table 3. Serum biochemical markers levels at baseline and 6 weeks of follow-up, and the mean difference

$2(95 \% \mathrm{CI})$ in serum marker change from baseline to 6 weeks in the vitamin D (VD) versus the placebo arm

3 as a reference.

4

\begin{tabular}{|c|c|c|c|c|c|}
\hline Serum marker & Week & $\begin{array}{l}\text { VD } \\
(n=37)\end{array}$ & $\begin{array}{l}\text { Placebo } \\
(n=38)\end{array}$ & $\begin{array}{l}\text { Mean difference }(95 \% \mathrm{CI}) \text { in } \\
\text { change from baseline to } 6 \text { weeks } \\
\text { in VD vs placebo arm }\end{array}$ & p value \\
\hline \multirow{2}{*}{$\begin{array}{l}\text { 25(OH)D level } \\
(\mathrm{ng} / \mathrm{mL})\end{array}$} & 0 & $17.2 \pm 4.8$ & $16.6 \pm 4.1$ & & \\
\hline & 6 & $41.8 \pm 9.1$ & $18.1 \pm 4.6$ & $23.1(19.7-26.4)$ & $<0.001$ \\
\hline \multirow[t]{2}{*}{ AST (U/L) } & 0 & $29.6 \pm 16.0$ & $28.9 \pm 10.9$ & & \\
\hline & 6 & $29.9 \pm 15.6$ & $30.0 \pm 12.5$ & $-0.7(-4.2-2.8)$ & 0.69 \\
\hline \multirow[t]{2}{*}{ ALT (U/L) } & 0 & $23.5 \pm 11.0$ & $23.7 \pm 10.0$ & & \\
\hline & 6 & $23.8 \pm 11.1$ & $27.1 \pm 14.2$ & $-3.0(-7.5-15)$ & 0.20 \\
\hline \multirow{2}{*}{$\begin{array}{l}\text { TGF- } \beta 1 \text { level } \\
(\mathrm{ng} / \mathrm{mL})\end{array}$} & 0 & $16.3 \pm 6.6$ & $14.3 \pm 8.3$ & & \\
\hline & 6 & $16.8 \pm 7.6$ & $15.4 \pm 6.8$ & $-0.6(-2.8-1.7)$ & 0.63 \\
\hline \multirow{2}{*}{$\begin{array}{l}\text { TIMP-1 level } \\
(\mathrm{ng} / \mathrm{mL})\end{array}$} & 0 & $236.9 \pm 50.0$ & $231.9 \pm 50.3$ & & \\
\hline & 6 & $244.0 \pm 66.0$ & $244.5 \pm 63.6$ & $-5.5(-26.4-15.3)$ & 0.60 \\
\hline \multirow{2}{*}{$\begin{array}{l}\text { MMP-9 level } \\
(\mathrm{ng} / \mathrm{mL})\end{array}$} & 0 & $576.2 \pm 296.2$ & $570.1 \pm 477.7$ & & \\
\hline & 6 & $684.3 \pm 423.5$ & $555.2 \pm 290.5$ & $122.9(-69.0-314.8)$ & 0.21 \\
\hline \multirow{2}{*}{$\begin{array}{l}\text { P3NP level } \\
(\mathrm{ng} / \mathrm{mL})\end{array}$} & 0 & $28.6 \pm 5.7$ & $28.0 \pm 4.3$ & & \\
\hline & 6 & $27.6 \pm 6.4$ & $27.2 \pm 4.3$ & $-0.1(-2.4-2.2)$ & 0.92 \\
\hline
\end{tabular}

5

6 *VD: vitamin D; 25(OH)D: 25-hydroxyvitamin D; AST: aspartate aminotransferase; ALT: alanine

7 aminotransferase; TGF- $\beta 1$ : transforming growth factor beta 1; TIMP-1: tissue inhibitor of matrix

8 metalloproteinase-1; MMP-9: matrix metalloproteinase 9; P3NP: amino terminal type III procollagen

9 peptide 


\section{Table 4 (on next page)}

Sensitivity analysis

The median $\left(25^{\text {th }}-75^{\text {th }}\right.$ percentile) serum biochemical marker levels at baseline and 6 weeks, and the median change $(95 \% \mathrm{Cl})$ in serum biochemical marker levels from baseline to 6 weeks of follow-up, in the VD versus the placebo arm as a reference, from median quantile regression 
1 Table 4. Sensitivity analysis showing the median $\left(25^{\text {th }}-75^{\text {th }}\right.$ percentile $)$ serum biochemical marker levels at 2 baseline and 6 weeks, and the median change $(95 \% \mathrm{CI})$ in serum biochemical marker levels from baseline 3 to 6 weeks of follow-up, in the Vitamin D (VD) versus the placebo arm as a reference, from median quantile 4 regression.

\begin{tabular}{|c|c|c|c|c|c|}
\hline Serum Marker & Week & VD Median (IQR) & Placebo Median (IQR) & $\begin{array}{l}\text { Median difference } \\
(95 \% C I) \text { in change } \\
\text { from baseline to } 6 \text { weeks } \\
\text { in VD vs placebo arm }\end{array}$ & p value \\
\hline \multirow{2}{*}{$\begin{array}{l}25(\mathrm{OH}) \mathrm{D} \text { level } \\
(\mathrm{ng} / \mathrm{mL})\end{array}$} & 0 & $19.2(19.2-21.3)$ & $16.9(14-19.1)$ & & \\
\hline & 6 & $39.5(36.7-46.5)$ & $17.6(15.1-21.1)$ & $24.2(20.8-27.6)$ & $<0.001$ \\
\hline \multirow{2}{*}{$\begin{array}{l}\text { TGF- } \beta 1 \text { level } \\
(\mathrm{ng} / \mathrm{mL})\end{array}$} & 0 & $14.8(11.5-21.1)$ & $15.0(9.2-17.8)$ & & \\
\hline & 6 & $15.8(10.1-22.5)$ & $15.6(8.8-20.3)$ & $-1.5(-3.2-0.22)$ & 0.09 \\
\hline \multirow{2}{*}{$\begin{array}{l}\text { TIMP-1 level } \\
\text { (ng/mL) }\end{array}$} & 0 & $232.0(200.7-275.1)$ & $226.4(199.9-261.1)$ & & \\
\hline & 6 & $229.0(197.8-275.5)$ & $229.2(189.0-276.0)$ & $-13.2(-33.2-6.7)$ & 0.19 \\
\hline \multirow{2}{*}{$\begin{array}{l}\text { MMP-9 level } \\
(\mathrm{ng} / \mathrm{mL})\end{array}$} & 0 & $584.8(345.2-802.1)$ & $449.4(339.0-637.5)$ & & \\
\hline & 6 & $615.1(329.5-890.8)$ & $486.0(363.7-721.7)$ & $-9.2(-146-127.7)$ & 0.89 \\
\hline \multirow{2}{*}{$\begin{array}{l}\text { P3NP level } \\
(\mathrm{ng} / \mathrm{mL})\end{array}$} & 0 & $27.0(26.1-31.0)$ & $28.1(25.6-31.0)$ & & \\
\hline & 6 & $25.8(24.1-28.8)$ & $26.6(23.8-29.7)$ & $-0.1(-2.8-2.5)$ & 0.92 \\
\hline
\end{tabular}

5

6

7 *VD: vitamin D; 25(OH)D: 25-hydroxyvitamin D; TGF- $\beta 1$ : transforming growth factor beta 1; TIMP-1:

8 tissue inhibitor of matrix metalloproteinase-1; MMP-9: matrix metalloproteinase 9; P3NP: amino terminal

9 type III procollagen peptide 
Figure 1

Screening, randomization, and follow-up

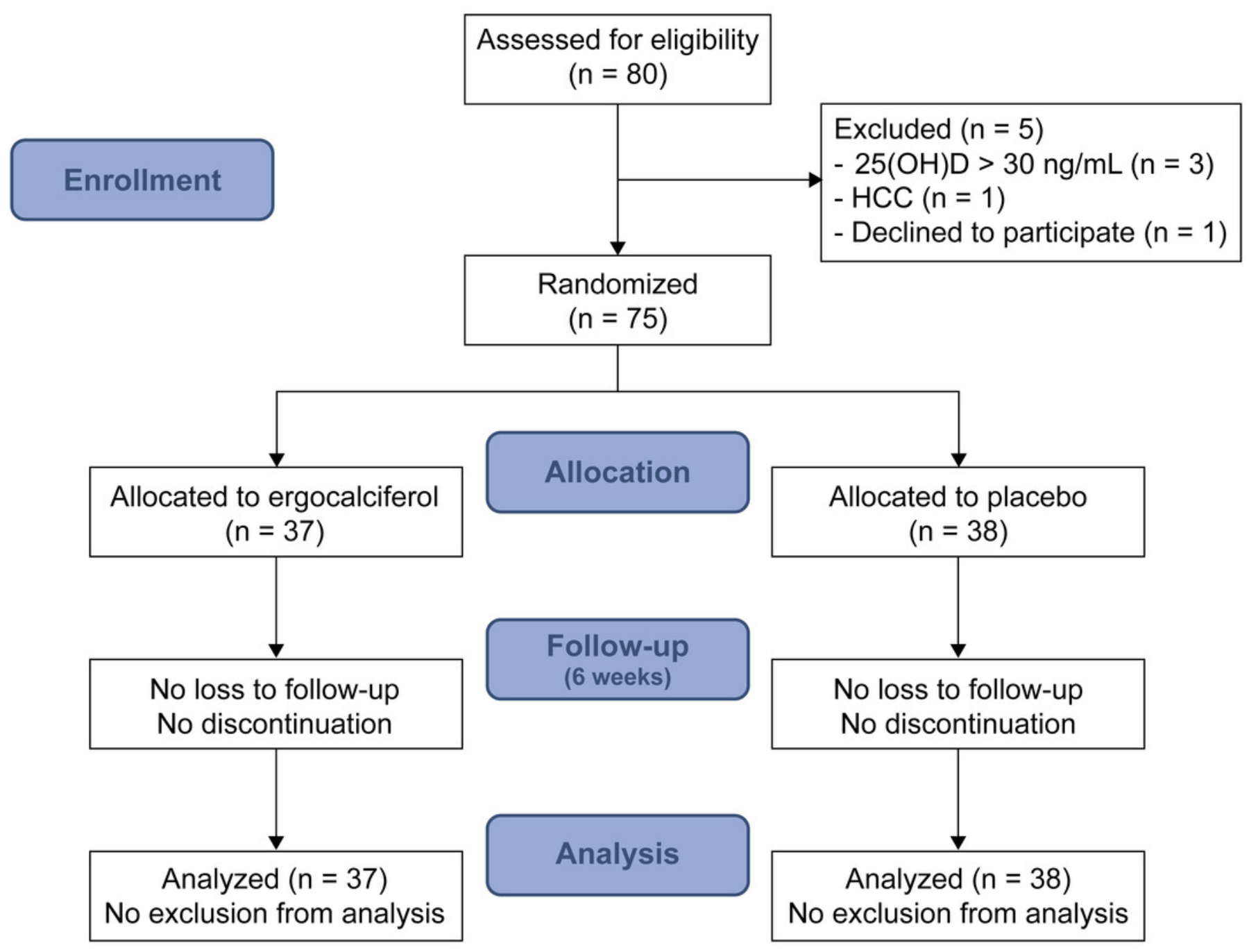


Figure 2

Box plot of serum 25(OH)D at baseline and after VD or placebo supplementation for 6 weeks

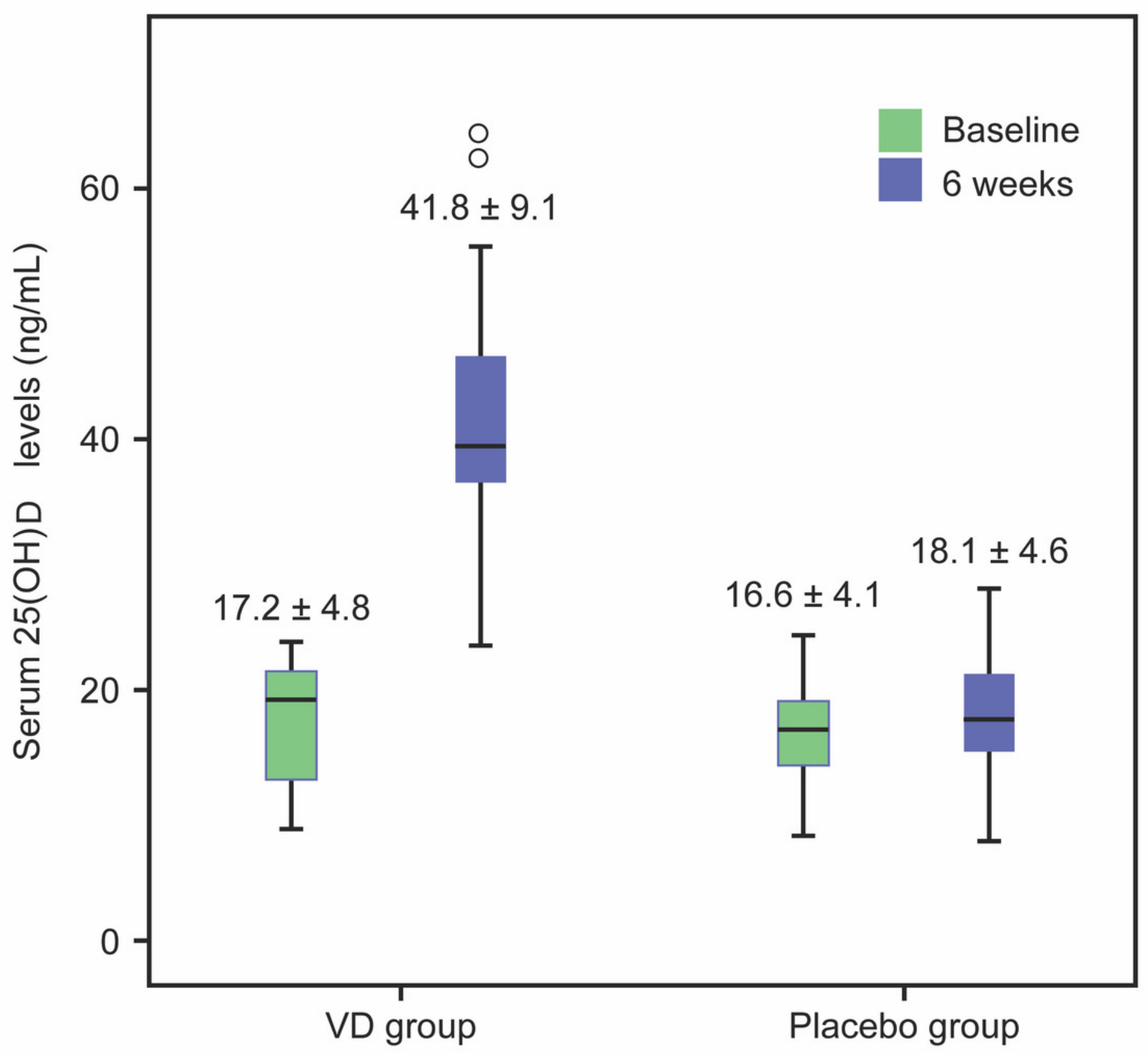




\section{Figure 3}

Line plot showing the individual serum marker levels for each patient connected with the levels at 6 weeks by randomized treatment arm. The overall median and mean levels at weeks 0 and 6 are connected by a dashed and solid line, respectively.
(A) TGF- $\beta 1$. (B) TIMP-1. (C) MMP-9. (D) P3NP.

Figure $A$ - TGF- $\beta 1$ concentration $(\mathrm{ng} / \mathrm{mL})$

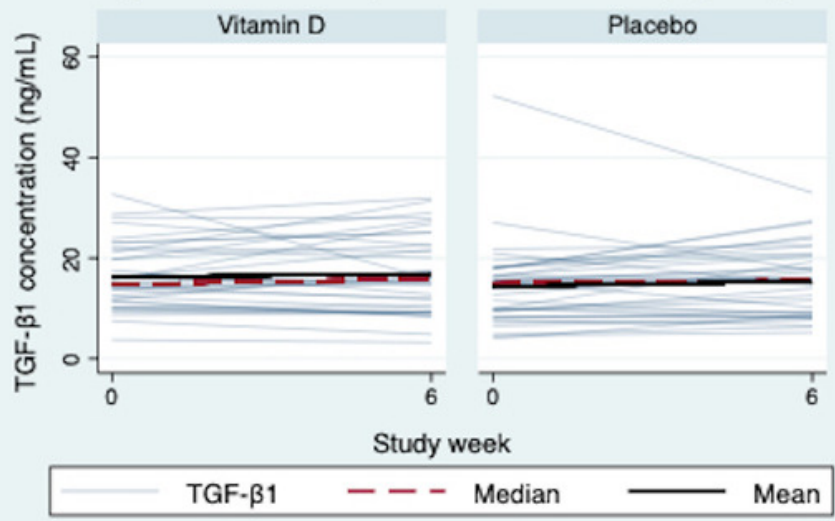

Figure C - MMP-9 concentration (ng/mL)

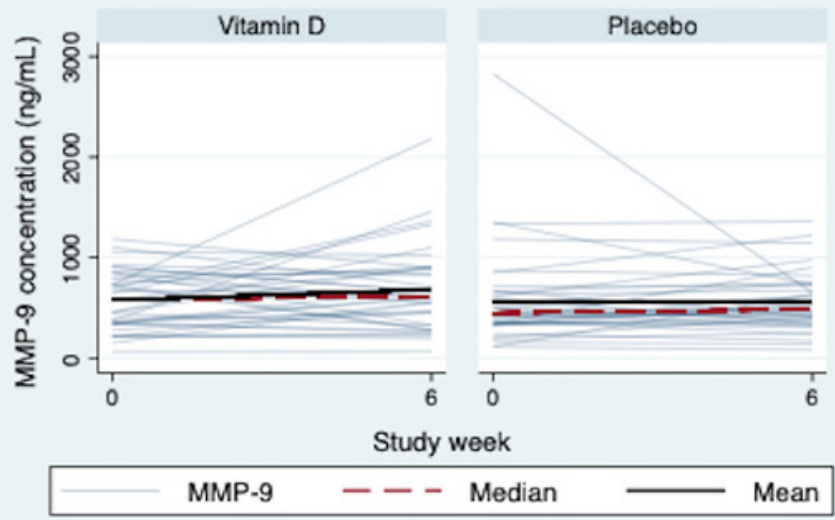

Figure B - TIMP-1 concentration ( $\mathrm{ng} / \mathrm{mL}$ )

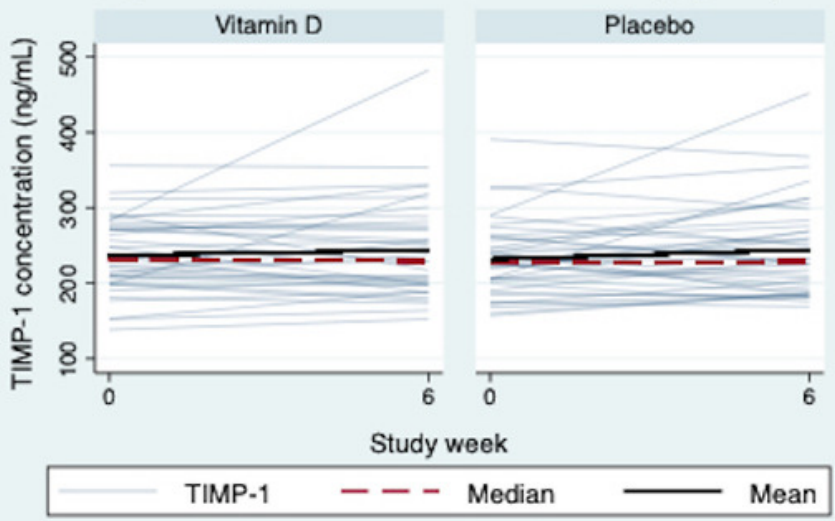

Figure D - P3NP concentration $(\mathrm{ng} / \mathrm{mL})$

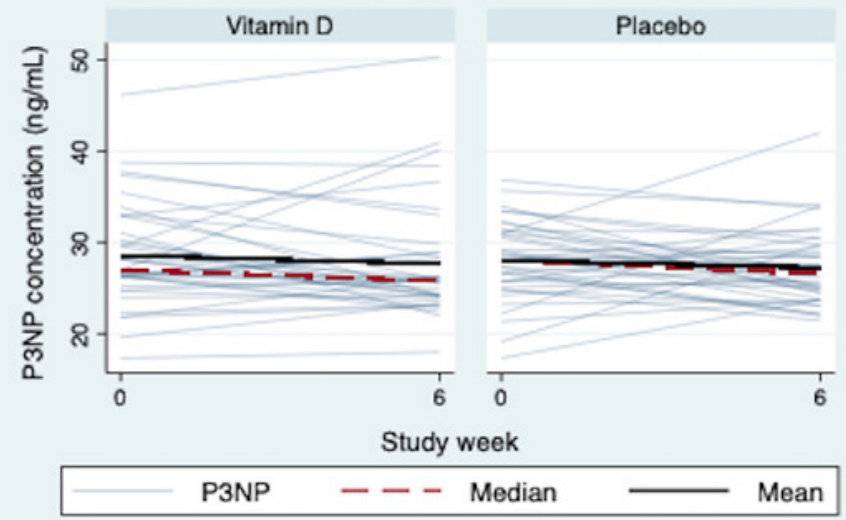

